\title{
Uma Visão para o Ensino Médio dos Conceitos Inerentes aos Processos Químicos
}

\author{
Afonso, H. M. C. ${ }^{1}$; Costa Jr., E. F. ${ }^{2}$; Costa, A. O. S. ${ }^{2}$ \\ 1 Graduação em Engenharia Química, Universidade Federal do Espírito Santo, Alegre, ES, Brasil \\ 2 Programa de Pós-Graduação em Engenharia Química, Curso de Graduação em Engenharia Química \\ Departamento de Engenharia Rural, CCA, Universidade Federal do Espírito Santo - UFES, Alegre , ES, Brasil
}

\begin{abstract}
Resumo
Neste trabalho são apresentados, às alunas do ensino médio da rede pública de ensino do ES, conceitos inerentes aos processos químicos. Para isto, os conceitos teóricos foram explorados empregando-se aulas teóricas e montagem experimental. Os conceitos trabalhados ampliam o conhecimento usualmente ofertado no ensino médio e motiva a participação dos alunos na elaboração de estudos mais avançados.
\end{abstract}

Keywords (Palavras chaves): balanço de massa, montagem experimental, simulação.

\section{Introdução}

Algumas iniciativas do governo federal do Brasil objetivam a ampliação do número de profissionais com formação na área tecnológica. 0 presente trabalho caracteriza-se como uma destas iniciativas (Edital MCTI/CNPq/SPM-PR/Petrobras 18/2013; Processo: 409956/2013-9). O objetivo geral deste trabalho consiste em apresentar às alunas do ensino médio da rede pública do ES aspectos inerentes aos processos químicos industriais, incentivando assim o ingresso destas alunas na universidade.

A utilização de aulas experimentais no nível médio é um recurso didático eficaz, uma vez que propõe aos alunos um maior entendimento da teoria, motivando-os a aprender mais sobre o assunto, e uma melhor qualificação ${ }^{1,2}$. Portanto, o desenvolvimento deste projeto alia conceitos teóricos com montagens experimentais. Os conceitos fundamentais dos processos químicos trabalhados neste estudo envolvem os princípios da conservação da massa ${ }^{3,4,5,6}$ e o efeito da coluna de líquido sobre a vazão de saída de líquido em um tanque ${ }^{7}$. Ressalta-se que tais conceitos se mostram presentes na grande maioria dos processos reais industriais ${ }^{4,5,6}$.

\section{Materiais e Métodos}

Os conceitos de vazões volumétricas, velocidade de escoamento de um líquido por um furo, balanços de massa e densidade foram apresentados, aliando a teoria com montagem experimental (ME), Figura 1. A ME empregada foi proposta, calibrada e os dados experimentais foram coletados contanto com a participação das alunas do ensino médio. O procedimento experimental seguiu as seguintes etapas: (i) o tanque era inicialmente preenchido com água até a altura máxima de $0,155 \mathrm{~m}$ (ho), que corresponde a $5 \mathrm{~L}$; (ii) a torneira (ponto 1, Figura 1) era totalmente aberta e o cronômetro era disparado; (iii) em alturas previamente definidas $(\mathrm{h})$, os valores de tempo $(\mathrm{t})$ eram coletados; (iv) o experimento encerrava-se quando a coluna de líquido atingia um altura de $0,035 \mathrm{~m}$, localizada acima da torneira.

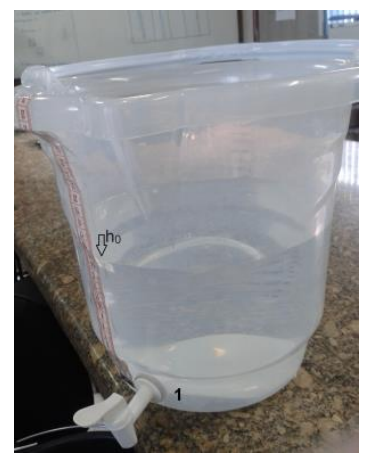

Figura 1: Montagem experimental empregada no projeto.

A dinâmica do sistema foi analisada através dos dados experimentais e de modelagem matemática (balanço de massa dinâmico). Para a modelagem do processo considerou-se: (i) o tanque possui um diâmetro constante igual a $0,28 \mathrm{~m}$ e uma área $A_{t}$; (ii) 0 diâmetro de saída (na torneira) é igual a 0,008m e uma área $A_{s}$. (iii) a densidade do sistema é constante ao longo do tempo; (iv) a resistência à passagem de fluido na torneira foi desconsiderada. Foram analisadas duas situações. 
$\mathrm{Na}$ primeira, a vazão de saída $\left(\mathrm{v}_{\mathrm{s}}\right)$ foi considerada constante e igual a $4,065 \times 10^{-5} \mathrm{~m}^{3} / \mathrm{s}$ $(41 \mathrm{~mL} / \mathrm{s})$. Neste caso, o efeito da coluna de líquido sobre a vazão de saída foi desconsiderado. A solução da equação diferencial ordinária, resultante da aplicação do balanço de massa, é apresentada na Equação (1).

$\mathrm{h}=\mathrm{h}_{0}-\frac{\mathrm{v}_{\mathrm{s}}}{\mathrm{A}_{\mathrm{t}}}, \mathrm{t}$

$\mathrm{Na}$ segunda situação, o efeito da coluna de líquido sobre a vazão de saída foi considerado ${ }^{7}$. Sendo assim, a solução da equação diferencial ordinária, resultante da aplicação do balanço de massa, é apresentada na Equação (2), onde g é a gravidade.

$h=\left[h_{0}^{\frac{1}{2}}-\frac{A_{g}}{A_{\mathrm{t}} \times 2} \times(2 \times g) \frac{2}{2} \times t\right]^{2}$

\section{Resultados e Discussão}

Os resultados obtidos neste trabalho, Figuras 1 e 2, foram apresentados e discutidos com as alunas do ensino médio.

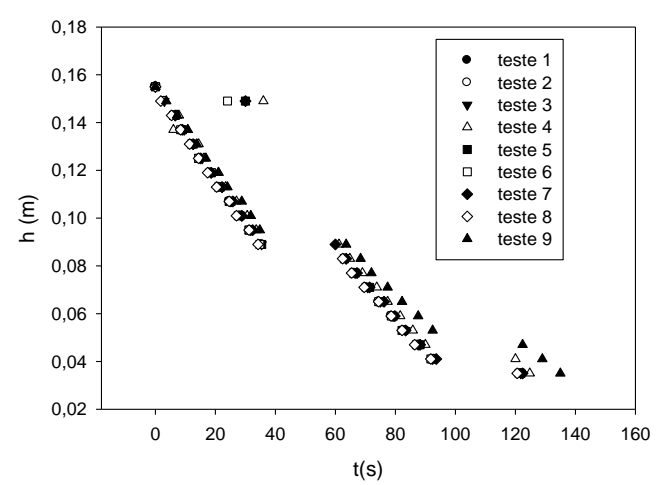

Figura 2: Valores experimentais da altura (h) em função do tempo (t).

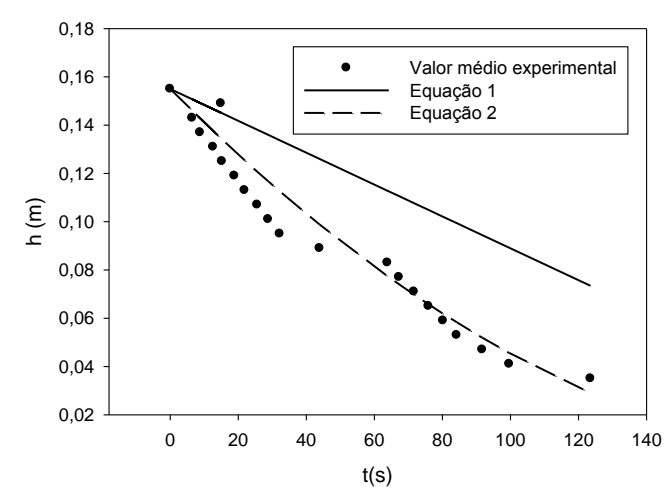

Figura 3: Comparação dos dados reais e os valores simulados.

Objetivando a efetiva participação das alunas envolvidas, foram realizadas 9 réplicas do experimento. Os resultados (Figura 2) evidenciam que foi possível uma satisfatória reprodutibilidade do processo. Ressalta-se que as aparentes descontinuidades, observadas para alturas de aproximadamente 0,09m e 0,04m, são explicadas considerando-se a não uniformidade do diâmetro do tanque.

Médias dos valores experimentais foram comparadas com os valores simulados empregando-se as Equações 1 e 2. Os resultados obtidos (Figura 3) evidenciam que, a adoção de uma vazão constante de saída não se mostrou adequada (Equação 1). Os melhores resultados foram obtidos quando foi considerado o efeito da altura de coluna de líquido na velocidade de saída do fluido (Equação 2).

\section{Conclusões}

Um aprofundamento nos conceitos teóricos, com o auxílio de aulas diversificas, é essencial para a formação de alunos qualificados e motivados pelo estudo. Especialmente considerando o processo de esvaziamento do tanque, foi possível aliar a teoria com a prática. Tal tarefa nem sempre se mostra corriqueira e desperta o interesse dos alunos para estudos mais avançados. Desta forma, com o desenvolvimento deste estudo, as alunas do ensino médio não só agregaram valores às disciplinas escolares; em especial física, química e matemática; como também desenvolvem interesse sobre o conteúdo.

\section{Agradecimentos}

Os autores agradecem ao $\mathrm{CNPq}$ pelo apoio financeiro ao projeto (Edital MCTI/CNPq/SPMPR/Petrobras 18/2013; Processo: 409956/2013-9) e pela bolsa de produtividade DTI. Estes agradecem ainda à FAPES pela bolsa Pesquisador Capixaba.

\section{Referências}

[1] LOBÔ, S. F.; MÜLLER, K. A. Z. Rev. Química Nova, v.35, p. 430-434, 2012.

[2] DE SOUSA, R. S.; ROCHA, P. P.; GARICIA, I. T. S. Rev. Química Nova, v.34, p. 220-228, 2012.

[3] HIMMELBLAU, D. M.; J. B., Engenharia Química Princípios e Cálculos, 7ª̣ed., Rio de Janeiro, LTC, 2006.

[4] Felder, R. M.; Rousseau, R. W. Princípios elementares dos processos químicos. $3^{\text {a }}$ edição, Rio de Janeiro: Editora LTC, 2005.

[5] Shreve, R. N., Brink, J. A., Indústrias de Processos Químicos, 4ªed., Guanabara Dois, Rio de Janeiro, 1980.

[6] Perry, R.H.; Green, D.W. Perry's Chemical Engineer's Handbook, 8th ed., McGraw-Hill, 2007.

[7] FOX, R. W.,McDONALD, A. T.,PRITCHARD, P. J., Introdução à Mecânica dos Fluidos, 6 ${ }^{\mathrm{a}}$ ed., Rio de Janeiro, LTC, 2006. 